\title{
Catalytic activity of mesoporous catalysts in Friedel-Crafts benzylation of benzene
}

\author{
Ahmed Arafat • Yahia Alhamed
}

Received: 7 January 2008/ Accepted: 26 June 2008

(C) Springer Science+Business Media, LLC 2008

\begin{abstract}
Different samples of metal-incorporated MCM41 were prepared and used as catalysts in Friedel-Craft's benzylation of benzene. The catalytic performance was evaluated by off-line GC analysis. Fe-MCM-41 exhibited excellent activity, the sample with $\mathrm{Si} / \mathrm{Fe}$ ratio $=10$ showed 90\% conversion with $95 \%$ selectivity towards diphenylmethane within a few minutes. Generally, the activity per Fe-site was an order of magnitude higher for the samples containing a combination of $\mathrm{Fe}_{2} \mathrm{O}_{3}$ nano-particles and isolated $\mathrm{Fe}^{3+}$ sites. A synergy of two catalytic centers (particles and isolated sites) is proposed to explain the high performance of the highly loaded samples. The catalytic performance of Fe-MCM-41 was superior to other metalcontaining MCM-41 (e.g. Ga, Sn, and Ti) catalysts, or other Fe-containing mesoporous materials (e.g. Fe-HMS).
\end{abstract}

Keywords Mesoporous - Fe-MCM-41 - Friedel-Crafts · Benzylation · Catalysis

\section{Introduction}

The electrophilic substitution reaction of alkyl groups in an aromatic system are known since 1877. Friedel-Crafts type reactions are considered as one of the most important reactions in organic synthesis. Benzylation of benzene using benzyl chloride to afford diphenylmethane is an interesting example as substitute for polychlorobenzene in the application of dielectrics.

A. Arafat $(\bowtie) \cdot$ Y. Alhamed

Chemical \& Materials Engineering Department,

Faculty of Engineering, King Abdulaziz University,

P.O. Box 80204, Jeddah 21589, Saudi Arabia

e-mail: akhamis@kau.edu.sa

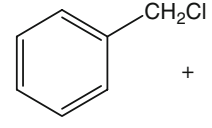

Benzyl chloride

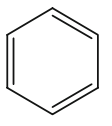

benzene

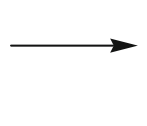

diphenylmethane
Although, homogeneous, Lewis or Brønsted acids were commonly used as catalysts in Friedel-Crafts type reactions [1] they create several problems such as polyalkylations and rearrangements which are difficult to avoid, in addition to corrosion, toxicity, and catalyst recovery. An important step forward to phase put these problems is the application of solid acid catalysts in these reactions.

A number of solid catalysts have been evaluated. Clark et al. [2, 3] reported montmorillonite-supported zinc (Clayzinc) and nickel chloride as highly active for catalyzing Friedel-Crafts alkylations. Another approach was clays $[4,5]$. Choudary found that iron pillared clays (FePILCs) were efficient catalysts, producing quantitative conversions with greatly reduced amounts of catalysts and shorter reaction times [6]. However, FePILCs were quite labile even under ambient conditions [7]. Aging the materials for periods of 3 months at $25^{\circ} \mathrm{C}$ resulted in a loss of the 011 ordering, redistribution of iron and a concomitant change in the degree of polycation polymerization. At the same time, the poor thermal stability of clay materials gives rise to difficulties in regeneration. Heteropolyacid salts [7-9] and zeolites (e.g. $\mathrm{HY}$ [10], and $\mathrm{H}-\beta$ [11]) were also used as catalysts for Friedel-Crafts reactions. It is interesting to mention that, in spite of its very strong acidity, zeolite H-ZSM-5 shows little or no activity in the benzylation of benzene [10]. On the other hand, Fe-ZSM-5 was also reported [12] and its catalytic activity was better than that of clays, however, the reaction was slow.

The use of metal-containing mesoporous materials as catalysts has also been reported [13, 14]. Their activities, 
although better, still did not lead to complete conversions over a period of $4 \mathrm{~h}$ or so. In the case of Fe-HMS the onedimensional pore structure might introduce less than optimal diffusion to and from the active centers. The nature of the active sites might also be an issue, as completely isolated iron atoms may not be the most favourable sites. Indeed, nanosized $\mathrm{Fe}_{2} \mathrm{O}_{3}$ clusters could be proven to be more reactive due to their high degree of coordinative unsaturation.

In this work, the catalytic performance of M-MCM-41 $(\mathrm{M}=\mathrm{Fe}, \mathrm{Ga}, \mathrm{Sn}$ and $\mathrm{Ti}$ ) was evaluated in the liquid phase Friedel-Crafts benzylation of benzene. The effects of metal loading and reaction temperature were evaluated. Moreover, a reaction mechanism based on a kinetic study is given as well.

\section{Experimental}

\subsection{Preparation and characterization of catalysts}

Fe-MCM-41 samples with 4 different $\mathrm{Si} / \mathrm{Fe}$ ratio of $(100,50$, 20 and 10) were used for this study. MCM-41 materials were synthesized applying a modified Stöber's synthesis of monodisperse silica spheres [15]. Typically, $2.5 \mathrm{~g}$ of $n$-hexadecyltrimetilammonium bromide $\left(\mathrm{C}_{16} \mathrm{TMABr}\right.$, Aldrich) was dissolved in $46.3 \mathrm{~g}$ of de-ionized water and mixed with $60 \mathrm{~g}$ of absolute ethanol. To this clear solution $16.9 \mathrm{~g}$ of aqueous ammonia solution $(25 \mathrm{~m} / \mathrm{m} \%)$ was added while stirring. Stirring was continued for another $15 \mathrm{~min}$. This followed by addition of $4.7 \mathrm{~g}$ of tetraethylorthosilicate (TEOS, Aldrich 98\%). The resulting hydrogel having the molar composition of 1 TEOS:0.3 $\mathrm{C}_{16}$ TMABr: $11 \mathrm{NH}_{3}$ : $144 \mathrm{H}_{2} \mathrm{O}: 58 \mathrm{EtOH}$ was stirred for $2 \mathrm{~h}$ and aged for additional $16 \mathrm{~h}$ at room temperature. Template removal was carried out by calcinations of samples under nitrogen up to $773 \mathrm{~K}$ at a heating rate of $2 \mathrm{~K} / \mathrm{min}$, followed by isothermal treatment at the same temperature for $2 \mathrm{~h}$ in air.

Fe-MCM-41 samples with various iron contents were prepared by slightly modifying the original procedure in order to avoid the precipitation of iron-hydroxides in the strongly alkaline medium. $\mathrm{C}_{16} \mathrm{TMABr}$, water, ethanol and TEOS were mixed in the desired proportion. To this solution 0.46 or $0.18 \mathrm{~g}$ of $\mathrm{Fe}\left(\mathrm{NO}_{3}\right)_{3} \cdot 9 \mathrm{H}_{2} \mathrm{O}(\mathrm{Si} / \mathrm{Fe}=20$ and $\mathrm{Si} / \mathrm{Fe}=50$, respectively, Fluka) was added and stirred for 30 min resulting in a light yellow, clear solution. The required amount of ammonia was poured into this solution at one time causing immediate gel precipitation. The color of the precipitate was pale beige. Calcination was carried out at $790 \mathrm{~K}$ with the same procedure as described above.

\subsection{Catalyst characterization}

$\mathrm{XRD}$ patterns were recorded using $\mathrm{Cu} \mathrm{K} \alpha$ radiation $(1=1541 \mathrm{~nm})$ on a Philips PW 1840 diffractometer equipped with a graphite monochromator. The samples were scanned over the range of $0.1-80^{\circ} 2 \theta$ with steps of $0.02^{\circ}$.

Nitrogen sorption isotherms were recorded on a Quantachrome Autosorb-6B at $77 \mathrm{~K}$. Mesoporosity was calculated from the adsorption branch using the Barret-JoynerHalaenda (BJH) model.

Diffuse reflectance UV-Vis spectra were recorded on a CaryWin 300 spectrometer under atmospheric conditions using $\mathrm{BaSO}_{4}$ as reference. Samples were scanned from 190 to $800 \mathrm{~nm}$. The UV-Vis absorption data were converted to Kubelka-Munk units using the following formula:

$\mathrm{F}(\mathrm{R})=\frac{(1-\mathrm{R})^{2}}{2 \mathrm{R}}$

Elemental analysis was carried out by using instrumental neutron activation analysis (INAA) [16] on a THER nuclear reactor with a thermal power of 2.0 MW and a maximum neutron reflux of $2.10 \mathrm{~m}^{-2} \mathrm{~S}^{-1}$. INAA was applied because of difficulties in dissolving the samples. The method proceeds in three steps, irradiation of the elements with neutrons in the nuclear reactor, followed by a period of decay, and finally a measurement of the radioactivity resulting from irradiation.

\subsection{Catalytic tests}

The liquid phase Friedel-Crafts benzylation reaction over Fe-MCM-41 was carried out in a magnetically stirred round-bottomed flask fitted with a reflux condenser and heated in a temperature-controlled oil bath. In a typical reaction, $0.1 \mathrm{~g}$ of catalyst (which had been activated overnight at $180^{\circ} \mathrm{C}$ ) was introduced into the reaction flask and heated for a couple of hours at $120^{\circ} \mathrm{C}$ in vacuum. The reaction flask was cooled down until the desired reaction temperature (in the range of $40-80{ }^{\circ} \mathrm{C}$ ) was reached. Then, dried $\mathrm{N}_{2}$ gas was bubbled through the reaction flask to avoid the effect of moisture. After that, $10 \mathrm{~mL}$ of benzene (dried over molecular sieves) and $1.0 \mathrm{~g}$ of benzyl chloride were added; this moment was considered the $t_{0}$ of the reaction. Liquid samples (in total, never more than $10 \%$ of the reaction volume) were taken at regular intervals and analyzed by gas chromatography. A Varian Star 3500 with a Sil 5 CB capillary column (50 m length, $0.53 \mathrm{~mm}$ inner diameter) was used, applying a helium carrier gas with 5 psi flow pressure. The chromatograph was equipped with a flame ionization detector. The mass balance of the reaction was closed within $3 \%$.

The method suggested by Sheldon et al. [17] was applied to study the stability of Fe-MCM-41. The leaching experiment was carried out for the Fe-2 sample by separating the solid catalyst after $1 \mathrm{~h}$ by filtration, which was carried out at the reaction temperature, using a micromembrane filter. The filtrate was quickly returned to the 
original flask allowing the reaction to proceed further. The solid residue was sent to elemental analysis for quantitative evaluation using neutron activation analysis (INAA).

\section{Results and discussion}

\subsection{Structure of the catalysts}

Fe-MCM-41 Fe-MCM-41 samples with 4 different $\mathrm{Si} / \mathrm{Fe}$ $\mathrm{wt} \%(100,50,20$ and 10) were named as Fe-1, Fe-2, Fe-5 and Fe-10, respectively. Other M-MCM-41 ( $\mathrm{M}=\mathrm{Ga}$, Sn and $\mathrm{Ti}$ ) are also listed in Table 1.

The elemental analysis and the porosity measurements obtained from $\mathrm{N}_{2}$ adsorption measurements at $77 \mathrm{~K}$ are listed in Table 1. Elemental analysis showed that the $\mathrm{Si} / \mathrm{Fe}$ ratio obtained after calcination is quite similar to that present in the synthesis gel, which indicates that most of Fe cations are incorporated into the solid final product. All FeMCM-41 samples showed type IV adsorption isotherms, indicative for meso-structured character [18]. The pore structure parameters of Fe-MCM-41 showed that the surface area increases with Fe content, while the pore volume and pore diameter decreased.

Figure 1 depicts XRD patterns of various samples of Fe-MCM-41 as compared with iron oxide $\left(\mathrm{Fe}_{2} \mathrm{O}_{3}\right)$ pattern. All Fe-MCM-41 samples showed a single intensive peak at low angle, indicating that Fe-MCM-41 is a meso-structured material. This peak shifted in accordance with the d-spacing of each sample. The peak intensity slightly decreases with the Fe-loading, indicating an influence of iron-loading on the integrity of the mesoporous structure. Additionally no bulk $\mathrm{Fe}_{2} \mathrm{O}_{3}$ or other phases could be detected in any of the prepared samples.

Figure 2 shows the diffuse reflectance UV-Vis spectra of the Fe-MCM-41 samples. All samples exhibit a peak around $260 \mathrm{~nm}$. This band is assigned to the charge transfer between the $\mathrm{Fe}^{3+}$ and $\mathrm{O}^{2-}$ atoms in the framework of $\mathrm{Fe}-\mathrm{O}-\mathrm{Si}$, indicating isolated, tetrahedrally-coordinated $\mathrm{Fe}$ species [19].

Table 1 Description of the catalysts prepared

\begin{abstract}
a Specific surface area,
${ }^{\mathrm{b}}$ Mesopore volume and

${ }^{\mathrm{c}}$ Mesopore diameter
\end{abstract}

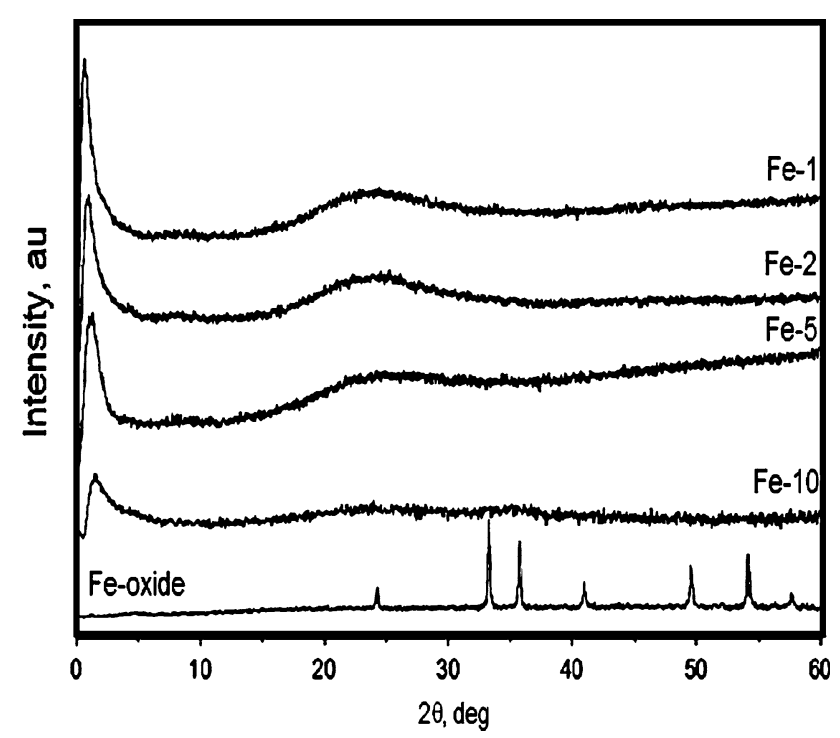

Fig. 1 X-ray diffraction patterns of the prepared Fe-MCM-41 samples

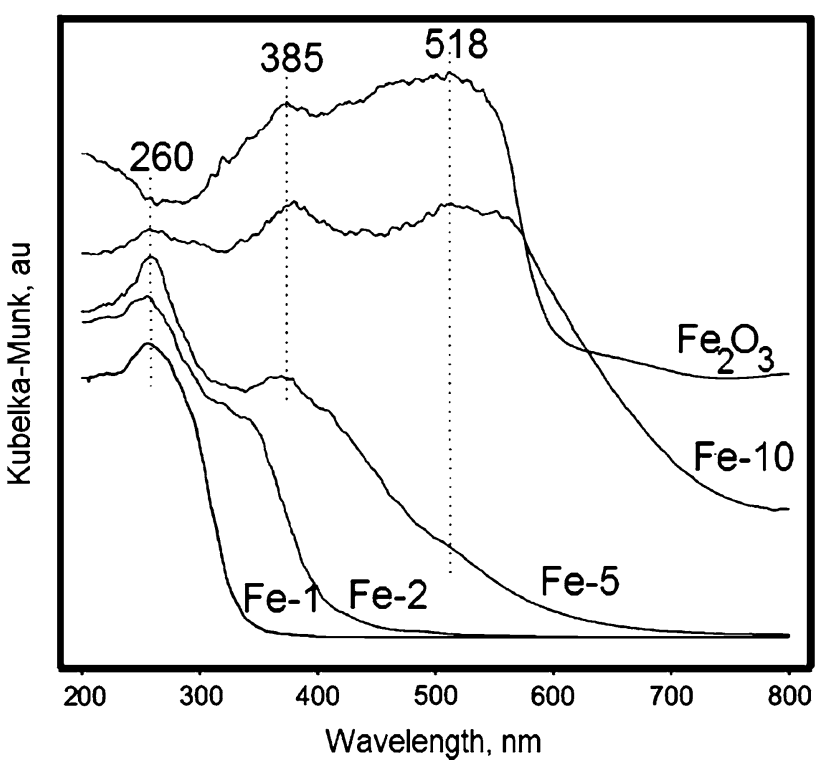

Fig. $2 \mathrm{UV}-\mathrm{V}$ is spectra for $\mathrm{Fe}-\mathrm{MCM}-41$ samples compared with $\mathrm{Fe}_{2} \mathrm{O}_{3}$

\begin{tabular}{|c|c|c|c|c|c|}
\hline \multirow[t]{2}{*}{ Sample } & \multicolumn{2}{|l|}{$\mathrm{Si} / \mathrm{M}$} & \multirow[t]{2}{*}{$\mathrm{S}_{\mathrm{BET}}^{\mathrm{a}}\left(\mathrm{m}^{2} / \mathrm{g}\right)$} & \multirow[t]{2}{*}{$\mathrm{V}_{\text {meso }}^{\mathrm{b}}\left(\mathrm{cm}^{3} / \mathrm{g}\right)$} & \multirow[t]{2}{*}{$\mathrm{D}_{\text {meso }}^{\mathrm{c}}(\mathrm{nm})$} \\
\hline & $\begin{array}{l}\text { Synthesis } \\
\text { mixture }\end{array}$ & $\begin{array}{l}\text { Calcined } \\
\text { product }\end{array}$ & & & \\
\hline $\mathrm{Fe}-1$ & 100 & 112 & 568 & 1.82 & 15.9 \\
\hline $\mathrm{Fe}-2$ & 50 & 52 & 625 & 1.24 & 11.5 \\
\hline $\mathrm{Fe}-5$ & 20 & 18 & 803 & 0.70 & 5.2 \\
\hline $\mathrm{Fe}-10$ & 10 & 10.1 & 874 & 0.45 & 3.7 \\
\hline $\mathrm{Ga}-2$ & 50 & 51 & 665 & 0.65 & 12.7 \\
\hline Sn-2 & 50 & 49.6 & 684 & 1.03 & 11.6 \\
\hline Ti-2 & 50 & 51.3 & 533 & 1.50 & 12.6 \\
\hline
\end{tabular}


In addition to this peak, a shoulder appeared at around $330 \mathrm{~nm}$ in the Fe-2 sample which would be consistent with the presence of polyferrate $(\mathrm{Fe}-\mathrm{O}-\mathrm{Fe})_{n}$ in the framework. At still higher $\mathrm{Fe}$ content, extra peaks were observed around 385 and $518 \mathrm{~nm}$ for the Fe-5 and Fe-10 samples, indicating the presence of either extra-framework iron or iron oxide particles at high $\mathrm{Fe}$ content [20].

\subsection{Effect of metal loading on the catalyst activity}

Table 2 shows the results of the Friedel-Craft's benzylation of benzene at $60{ }^{\circ} \mathrm{C}$ over several calcined Fe-MCM-41 mesoporous samples. Siliceous MCM- 41 and $\mathrm{Fe}_{2} \mathrm{O}_{3}$ were tested as reference materials. It is clear that siliceous MCM-41 does not catalyze the reaction at all and no products were detected. When bulk $\mathrm{Fe}_{2} \mathrm{O}_{3}$ was used as a catalyst, only a small conversion was achieved after $4 \mathrm{~h}$ which gave an indication that the dispersed $\mathrm{Fe}^{3+}$ containing mesoporous MCM-41 matrix is essential to catalyze this reaction.

\subsection{Reaction kinetics}

The rate data (time-dependent benzyl chloride conversion data) for the benzene benzylation reaction (with excess of benzene) over the Fe-MCM-41 catalysts could be fitted well to a pseudo-first-order rate law,

$\ln \left[\frac{1}{1-\mathrm{x}}\right]=\mathrm{k}\left(\mathrm{t}-\mathrm{t}_{0}\right)$

where $k$ is the first-order rate constant, $x$ is the fractional conversion of benzyl chloride, $t$ is the reaction time and $t_{0}$ is the induction period, corresponding to the time required for reaching the equilibrium temperature. A plot of $\log$ $(1 / 1-x)$ as a function of time gave a linear plot over a large range of benzyl chloride conversions (Fig. 3). These results are in agreement with the results reported elsewhere [21].

Table 2 Conversion of benzyl chloride at $60{ }^{\circ} \mathrm{C}$ over different Fe-MCM-41 samples compared with blank siliceous MCM-41 and $\mathrm{Fe}_{2} \mathrm{O}_{3}$

\begin{tabular}{lccc}
\hline Sample & Si/M & Conversion (\%) & $\begin{array}{l}\text { Reaction } \\
\text { time (min) }\end{array}$ \\
\hline MCM-41 & $\infty$ & 0 & 240 \\
$\mathrm{Fe}_{2} \mathrm{O}_{3}$ & 0 & 5 & 240 \\
$\mathrm{Fe}-1$ & 112 & 86 & 240 \\
$\mathrm{Fe}-2$ & 54 & 92 & 180 \\
$\mathrm{Fe}-5$ & 18 & 89 & 10 \\
$\mathrm{Fe}-10$ & 10.1 & 90 & $<1.5$ \\
$\mathrm{Ga}-2$ & 51 & 65 & 240 \\
$\mathrm{Sn}-2$ & 49.6 & 16 & 240 \\
$\mathrm{Ti}-2$ & 51.3 & 4 & 240 \\
\hline
\end{tabular}

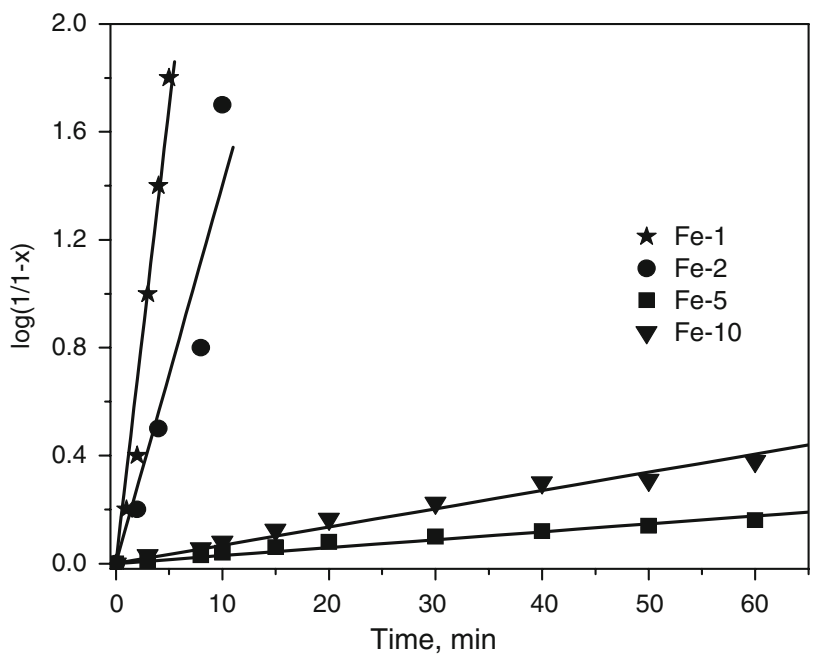

Fig. 3 Pseudo 1st order plots for the benzylation of benzene over different Fe-MCM-41 samples at $60{ }^{\circ} \mathrm{C}$

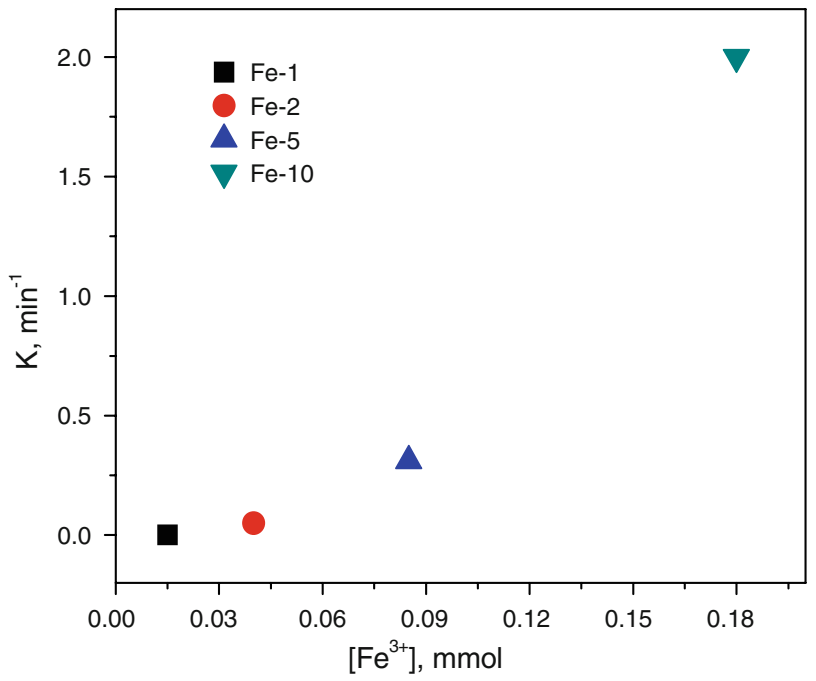

Fig. 4 The non-linear behaviour of different Fe-MCM-41 samples in catalytic activity, obtained by plotting the reaction rate constants as a function of active Fe sites

In Fig. 4, the rate constants were plotted against the concentration of Fe in the 4 samples of Fe-MCM-41, the relationship showed non-linear behaviour as indication for the change in the nature of the active sites.

\subsection{Effect of temperature and calculation of activation energy $(\mathrm{Ea})$}

To study the effect of temperature on the reaction rate, reactions were carried out at three different temperatures per sample. Figure 5 depicts the conversion of benzyl chloride over different Fe-MCM-41 samples at different temperatures. It is clear that the catalytic performance is strongly improved by increasing the reaction temperature. 
Fig. 5 The conversion of benzyl chloride over Fe-MCM41 samples at different temperatures
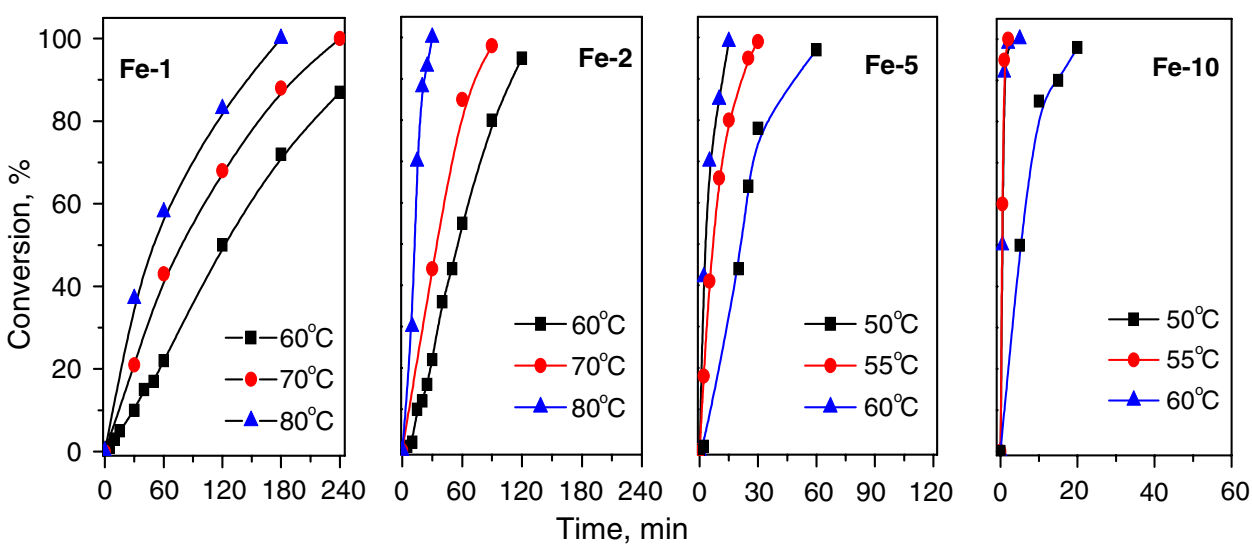

Table 3 Kinetic parameters for he benzylation of benzene over different Fe-MCM-41 samples

\begin{tabular}{|c|c|c|c|c|c|c|}
\hline \multirow[t]{2}{*}{ Sample } & \multicolumn{5}{|c|}{ First order rate constant $\mathrm{K}\left(10^{3} \mathrm{~min}^{-1}\right)$} & \multirow{2}{*}{$\begin{array}{l}\text { Activation energy } \\
\left(\mathrm{KJ} \mathrm{mol}^{-1}\right)\end{array}$} \\
\hline & 323 & 328 & 333 & 343 & 353 & \\
\hline $\mathrm{Fe}-1$ & - & - & 9 & 12 & 24 & 47 \\
\hline $\mathrm{Fe}-2$ & - & - & 22 & 45 & 120 & 85 \\
\hline $\mathrm{Fe}-5$ & 40 & 100 & 310 & - & - & 182 \\
\hline $\mathrm{Fe}-10$ & 194 & 601 & 2167 & - & - & 216 \\
\hline
\end{tabular}

The rate constants at different temperatures for the different Fe-MCM-41 samples are listed in Table 3.

The activation energy was calculated from the Arrhenius equation:

$\mathrm{K}=\mathrm{A} \exp ^{\frac{-\mathrm{Ea}}{\mathrm{RT}}}$

From the above equation at two different temperatures follows:

$\ln \frac{\mathrm{K}_{1}}{\mathrm{~K}_{2}}=\frac{\mathrm{E}_{\mathrm{a}}}{\mathrm{R}}\left[\frac{1}{\mathrm{~T}_{2}}-\frac{1}{\mathrm{~T}_{1}}\right]$

where $A$ is the frequency factor $\left(\mathrm{min}^{-1}\right), E a$ is the activation energy $\left(\mathrm{kJ} \mathrm{mol}^{-1}\right), R$ is the universal gas constant $\left(8.314 \mathrm{~J} \mathrm{~mol}^{-1} \mathrm{~K}^{-1}\right.$ ) and $T$ is the reaction temperature $(K)$. In Fig. 6 the Arrhenius plots of the reaction is depicted.

The large difference in the activation energy of the Fe-1 and $\mathrm{Fe}-2$ samples versus the $\mathrm{Fe}-5$ and $\mathrm{Fe}-10$ samples might be explained by different kinetically rate determining steps, related to the presence of the nano-particles of Fe-oxide present in the catalysts. This will be further evaluated in the following paragraphs.

\subsection{Reaction mechanism}

The redox properties play an important role in the reaction mechanism of benzene benzylation [9]. It has been proposed that the reaction can be initiated by an oxidation of benzyl chloride over isolated $\mathrm{Fe}^{3+}$ with the formation of carbocations (Eq. 2) after radical formation was initiated in solution (Eq. 1); the carbocations can attack the aromatic substrate

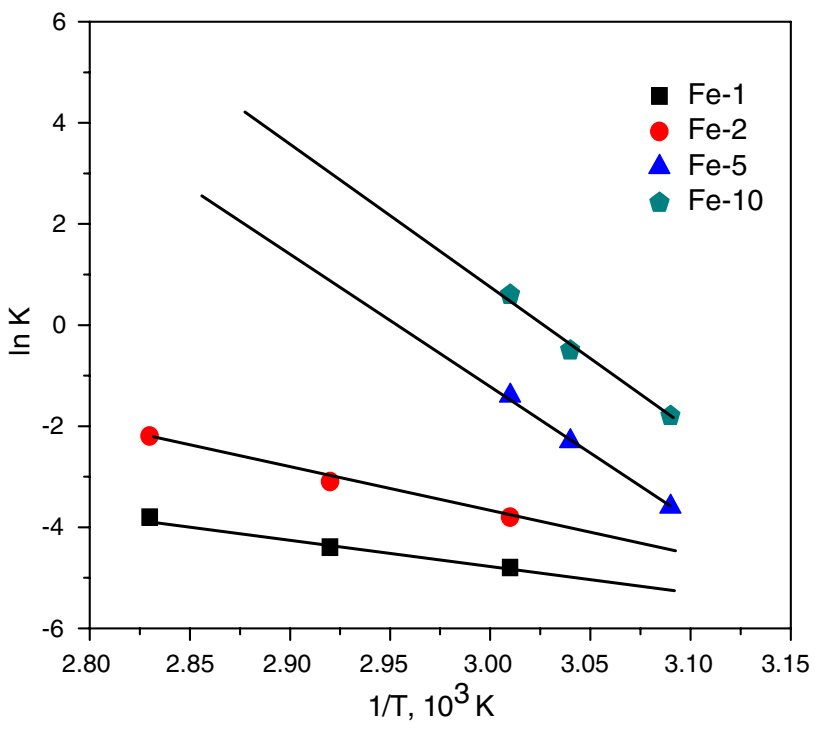

Fig. 6 Arrhenius plot for pseudo1st order rate constants

directly without activation (Eq. 3), as a normal electrophilic substitution reaction, to form the benzylated product. The reaction mechanism over $\mathrm{Fe}-1$ and $\mathrm{Fe}-2$ can be described as:

$\mathrm{C}_{6} \mathrm{H}_{5}-\mathrm{CH}_{2} \mathrm{Cl}+\mathrm{Fe}^{3+} \rightarrow \mathrm{C}_{6} \mathrm{H}_{5}-\mathrm{CH}_{2}^{\bullet+}+\mathrm{Cl}^{\bullet}$

$\mathrm{C}_{6} \mathrm{H}_{5}-\mathrm{CH}_{2}^{\bullet+} \rightarrow \mathrm{C}_{6} \mathrm{H}_{5}-\mathrm{CH}_{2}^{+}+\mathrm{Fe}^{2+}$

$\mathrm{C}_{6} \mathrm{H}_{5}-\mathrm{CH}_{2}^{+}+\mathrm{C}_{6} \mathrm{H}_{5}-\mathrm{H} \rightarrow \mathrm{C}_{6} \mathrm{H}_{5}-\mathrm{CH}_{2}-\mathrm{C}_{6} \mathrm{H}_{5}$

$\mathrm{Fe}^{2+}+{ }^{\bullet} \mathrm{Cl} \rightarrow \mathrm{Fe}^{3+}+\mathrm{Cl}^{-}$

Reaction (3), the electrophilic substitution of benzene, is the proposed rate determining step. The energy difference 
of $38 \mathrm{~kJ} / \mathrm{mol}$ between Fe-1 and Fe-2 samples is as yet not well understood, most probably it is due to experimental errors. Significantly still higher activation energy was observed for the Fe-5 and Fe-10 samples. To explain the latter, it can be hypothesized that the activation of benzene is catalysed by the nano-particles of Fe-oxide as follows:

$$
\begin{gathered}
\mathrm{C}_{6} \mathrm{H}_{5}-\mathrm{H} \\
+ \\
-\mathrm{Fe}-\mathrm{O}
\end{gathered}
$$
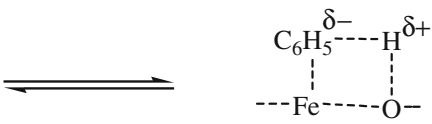

This step (proposed earlier in [22]) facilitates the reaction between the benzyl carbocation obtained in (2) and the activated benzene. Reaction (3) is now represented by reaction (6).

$\mathrm{C}_{6} \mathrm{H}_{5}-\mathrm{H}+\mathrm{C}_{6} \mathrm{H}_{5}-\mathrm{CH}_{2}^{+} \rightarrow \mathrm{C}_{6} \mathrm{H}_{5}-\mathrm{CH}_{2}-\mathrm{C}_{6} \mathrm{H}_{5}+\mathrm{H}^{+}$

It is clear that step (6) is much faster than the normal electrophilic substitution step (3). In view of the high activation energy, it can be hypothesized that now reaction (1) becomes rate determining. The proposed mechanism is schematically illustrated in Fig. 7. It is important to mention that for the newly proposed mechanism to be viable, the isolated sites and the nano-particles have to be located in close proximity. This is very likely to be the case in the MCM-41 catalysts, since the characterization results indicate that the nanoparticles are located inside the mesopores of MCM-41, whereas most of the isolated $\mathrm{Fe}^{3+}$ sites are incorporated in the surface of the pores of MCM-41[23].

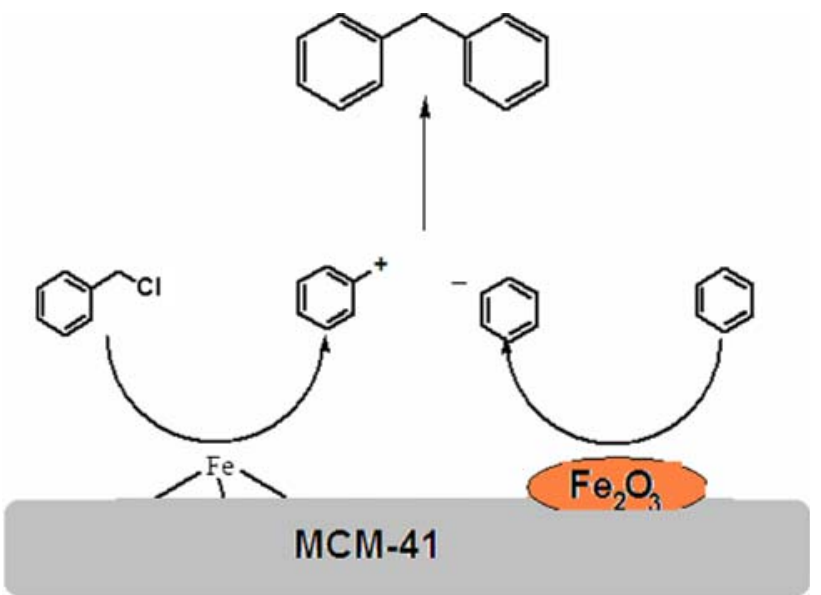

Fig. 7 Scheme of benzene benzylation catalyzed by Fe-MCM-41. The $\mathrm{Fe}^{3+}$ isolated sites activate the benzyl chloride and the $\mathrm{Fe}_{2} \mathrm{O}_{3}$ nano-particles activate the benzene ring. The two intermediates react relatively fast
Actually, the calculated activation energies are remarkable. Experimentally, the results obtained form the two sets of the reaction, which were controlled by GC are trustable. However, the fact that the kinetic data set is very limited and hence the reported activation energies have to be interpreted with caution. An argument in favor for the two sets of activation energies, is that the high activation energy was obtained for catalysts that clearly contain a significant amount of iron oxide nano-particles, whereas the lower activation energy was related to the catalysts which contain only isolated iron sites. Moreover, the calculated pre-exponential factor for Fe-10 is significantly larger (250 times higher) than Fe-1. Hence the presence of two different reaction mechanisms is, most likely, the suitable explanation.

\subsection{Stability of Fe in MCM-41 framework}

A leaching experiment showed that after separating the catalyst by hot-filtration, the reaction did not continue, the amount of benzyl chloride remaining constant (Fig. 8). However, elemental analysis showed that almost $33 \%$ of the $\mathrm{Fe}$ atoms have been removed from the framework (before $\mathrm{Si} / \mathrm{Fe}$ ratio $=64$, and after $=98$ ). This strongly suggests that the reaction proceeded heterogeneously and although Fe was leached, this did not initiate further conversion. Thus, Fe-MCM-41 catalysts represent category (II) of Sheldons' leaching classification [24], i.e. metal is leaching from the framework, but it does not catalyze the reaction.

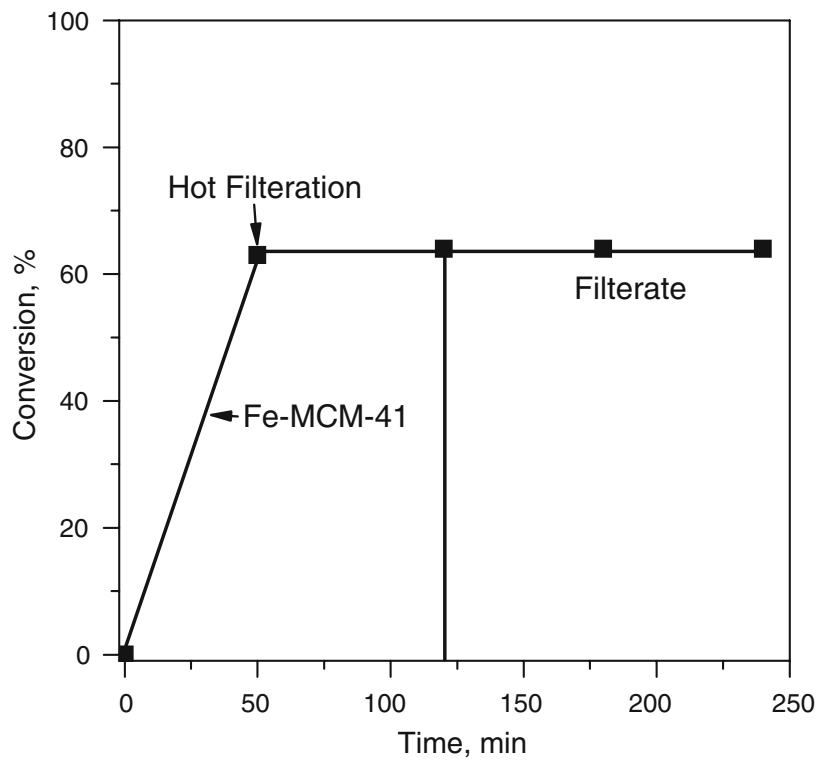

Fig. 8 Leaching experiment for benzyl chloride over $\mathrm{Fe}-2$, the catalyst has been hot-filtrated off after $1 \mathrm{~h}$ 
3.7 Comparison between Fe-MCM-41 and other catalysts

A comparison between the activity of Fe-MCM-41 with the activities of other mesoporous and microporous materials-as previously reported-is presented in Fig. 9, the reactions were carried out in comparable conditions.

Medium pore HZSM-5 and large pore $\mathrm{H} \beta$ and $\mathrm{HY}$ zeolites [25, 26] were reported to catalyze Friedel-Crafts benzylation of benzene. HZSM-5 showed the lowest activity due to diffusion limitations compared to $\mathrm{H} \beta$ and $\mathrm{HY}$ whereas $\mathrm{H} \beta$ and was more selective. Zeolite particle size and $\mathrm{Si} / \mathrm{Al}$ ratio were found to affect the rate benzyl chloride conversion and the reaction proceeds via intraparticle diffusion mechanism. Nevertheless, Fe-MCM-41 show much higher activities, most likely due to the combination of wider pore sizes and the improved local activities of the active sites.

Figure 9 clearly shows that Fe-10 sample has a remarkable high activity compared to reported FeMCM-41 [14]. Differences in the activities can be due to the different synthesis procedure. It posses smaller pore sizes compared to Fe-10. On the other hand, it contains replaceable or extra-framework Fe(III). These differences leaded to considerable lowering in the catalyst activities compared to our catalysts. Moreover, the highly dispersed $\mathrm{Fe}_{2} \mathrm{O}_{3}$ nanoparticles our catalyst is responsible for the notable activities of Fe-10.

The comparison showed that Fe-MCM-41 (whatever the loading is) was more active than other Fe-containing microporous materials. This can be attributed to the

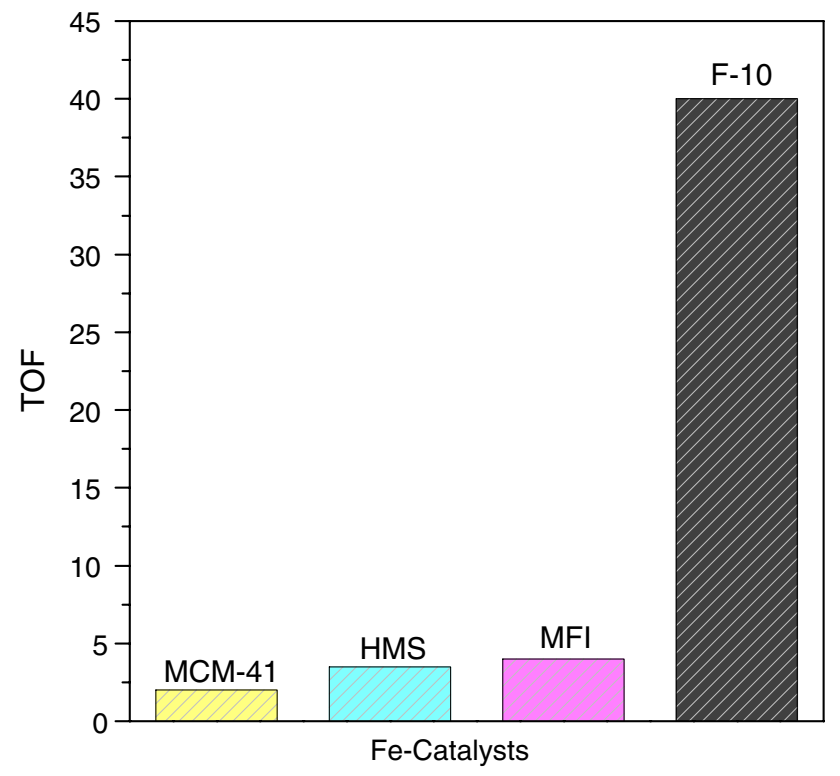

Fig. 9 Comparison between the catalytic activity (TOF) over different meso- and microporous catalysts reported as Fe-MCM-41 [14], Fe-HMS $[12,22]$ and Fe-MFI [12] with Fe-MCM-41 (Fe-10 sample) mesoporous structure of the catalysts which allows higher accessibility of the substrates. Wider pores which allow the easy movement of the substrate molecules towards the active sites and the simultaneous presence of iron oxide nano-particles as well as isolated iron species are unique for the MCM-41 matrix.

\section{Conclusions}

From the present study of the Friedel-Crafts' benzylation of benzene over M-MCM-41 ( $\mathrm{M}=\mathrm{Fe}, \mathrm{Ga}, \mathrm{Sn}$ and Ti), the following conclusions can be drawn:

(1) Fe-MCM-41 was the most active catalyst compared to other M-MCM-41 catalysts, due to the higher redox potential of $\mathrm{Fe}^{3+}$ incorporated in the MCM-41 silica matrix.

(2) In general, the Fe-MCM-41 samples with $\mathrm{Fe}_{2} \mathrm{O}_{3}$ nano-particles show very high activity, i.e. $100 \%$ conversion within 90-600 s. Based on a kinetic study, a synergy of two different active sites $\left(\mathrm{Fe}^{3+}\right.$ and $\mathrm{Fe}_{2} \mathrm{O}_{3}$ nanoparticles) might explain the high activity.

(3) Fe-MCM-41 with a wide pore system, allows high substrate accessibility, explaining the excellent performance compared to other Fe systems, such as Fe-HMS or Fe-ZSM-5.

\section{References}

1. Olah GA in Friedel-Crafts and related reactions, vol. 1, Chap. 1, (Wiley-Interscience, New York, 1963)

2. J.H. Clark, S.R. Cullen, S.J. Barlow, T.W. Bastock, J. Chem. Soc. Perkin. Trans. 2, 1117 (1994). doi:10.1039/p29940001117

3. J.H. Clark, A.P. Kybett, D.J. Macquarrie, S.J. Barlow, P. Landon, J. Chem. Soc. Chem. Commun. 1353 (1989). doi:10.1039/ c39890001353

4. M. Campanati, F. Fazzini, G. Fornasari, A. Tagliani, A. Vaccari, O. Piccolo, Chem. Ind. 75, 307 (1998)

5. T. Cseri, S. Bekassy, F. Figueras, S. Rizner, J. Mol. Catal. A 98, 101 (1995). doi:10.1016/1381-1169(95)00016-X

6. B. Choudary, M. Kantam, M. Sateesh, K. Rao, P. Santhi, Appl. Catal. A 149, 257 (1997). doi:10.1016/S0926-860X(96)00310-9

7. E. Rightor, M. Tzou, T. Pinnavaia, J. Catal. 130, 29 (1991). doi: 10.1016/0021-9517(91)90089-M

8. I. Yusuke, O. Mayumi, U. Kazuo, Appl. Catal. A 132, 127 (1995). doi:10.1016/0926-860X(95)00167-0

9. I. Yusuke, O. Mayumi, N. Wataru, U. Kazuo, Chem. Lett. 10, 1987 (1992)

10. B. Coq, V. Gourves, F. Figueras, Appl. Catal. A 100, 69 (1993). doi:10.1016/0926-860X(93)80116-8

11. A. Singh, D. Bhattacharya, Catal. Lett. 32, 327 (1995). doi: 10.1007/BF00813227

12. V.R. Choudhary, S.K. Jana, B.P. Kiran, Catal. Today 59, 217 (1999)

13. J. Cao, N. He, C. Li, J. Dong, Q. Xu, Stud. Surf. Sci. Catal. 117, 461 (1998) 
14. N. He, S. Bao, Q. Xu, Appl. Catal. A 169, 29 (1998). doi: $10.1016 / \mathrm{S} 0926-860 \times(97) 00347-5$

15. W. Stöber, A. Fink, E.J. Bohn, Colloid Interface Sci. 26, 62 (1968). doi:10.1016/0021-9797(68)90272-5

16. Boynton F, Neutron activation analysis. in Handbook on the Physics and Chemistry, Chap. 37F, ed. by J.K. Gschneidner, L. Eyring (Holland Publishing Company, Amsterdam, 1979), pp. 457-470

17. R.A. Sheldon, I.W. Arends, H.E. Lempers, Catal. Today 41, 387 (1998). doi:10.1016/S0920-5861(98)00027-3

18. K. Sing, D. Everett, R. Haul, L. Moscou, R. Pierotti, J. Rouquerol et al., Pure Appl. Chem. 57, 603 (1985). doi:10.1351/pac 198557040603

19. B. Echchahed, A. Moen, D. Nicholson, L. Bonneviot, Chem. Mater. 9, 1716 (1997). doi:10.1021/cm970241e
20. Y. Wang, Q. Zhang, T. Shishido, K. Takehira, J. Catal. 209, 186 (2002). doi:10.1006/jcat.2002.3607

21. K. Bachari, J. Millet, B. Benaichouba, O. Cherifi, F. Figueras, J. Catal. 221, 55 (2004). doi:10.1016/S0021-9517(03)00295-1

22. V.R. Choudhary, S.K. Jana, Appl. Catal. A 224, 51 (2002). doi: 10.1016/S0926-860X(01)00821-3

23. Z. Shan, J.C. Jansen, L. Marchese, T. Maschmeyer, Microporous Mesoporous Mater. 48, 181 (2001). doi:10.1016/S1387-1811 (01)00342-0

24. I.W. Arends, R.A. Sheldon, Appl. Catal. A 212, 175 (2001). doi: 10.1016/S0926-860X(00)00855-3

25. G. Bellussi, G. Pazzuconi, C. Perego, G. Girotti, G. Terzoni, J. Catal. 157, 227-234 (1995). doi:10.1006/jcat.1995.1283

26. V.D. Chaube, Catal. Commun. 5, 321-326 (2004). doi:10.1016/ j.catcom.2004.02.013 